\title{
Field Tests to Investigate the Penetration Rate of Piles Driven by Vibratory Installation
}

\author{
Zhaohui Qin, Longzhu Chen, Chunyu Song, and Lei Sun \\ Department of Civil Engineering, Shanghai Jiaotong University, Shanghai 200240, China \\ Correspondence should be addressed to Longzhu Chen; lzchen@sjtu.edu.cn
}

Received 26 October 2016; Revised 6 April 2017; Accepted 23 April 2017; Published 21 May 2017

Academic Editor: Fiorenzo A. Fazzolari

Copyright (C) 2017 Zhaohui Qin et al. This is an open access article distributed under the Creative Commons Attribution License, which permits unrestricted use, distribution, and reproduction in any medium, provided the original work is properly cited.

\begin{abstract}
Factors directly affecting the penetration rate of piles installed by vibratory driving technique are summarized and classified into seven aspects which are driving force, resistance, vibratory amplitude, energy consumption, speeding up at the beginning, pile plumbness keeping, and slowing down at the end, from the mechanism and engineering practice of the vibratory pile driving. In order to find out how these factors affect the penetration rate of the pile in three major actors of vibratory pile driving: (i) the pile to be driven, (ii) the selected driving system, and (iii) the imposed soil conditions, field tests on steel sheet piles driven by vibratory driving technique in different soil conditions are conducted. The penetration rates of three different sheet pile types having up to four different lengths installed using two different vibratory driving systems are documented. Piles with different lengths and types driven with or without clutch have different penetration rates. The working parameters of vibratory hammer, such as driving force and vibratory amplitude, have great influences on the penetration rate of the pile, especially at the later stages of the sinking process. Penetration rate of piles driven in different soil conditions is uniform because of the different penetration resistance including shaft friction and toe resistance.
\end{abstract}

\section{Introduction}

Vibratory pile driving is an alternative pile installation technique, and the pile is attached to a vibrator hammer and inserted into the ground by vertical vibration. This technique is used in temporary and permanent foundation systems and earth-retaining structures. In comparison to the impact driving, installation of piles with vibratory driving system produces less noise and damage to the pile. And the pile has significant faster penetration rate in favorable soil conditions [1-4]. The main types of vibratory driving systems are freehanging, leader-mounted, and excavator driving systems [5].

Because of these advantages, vibratory driving technique is used in almost each type of soils, such as sands and clays, even in permafrost in the Alaskan arctic $[6,7]$, and in peat deposits [8]. The vibratory driving technique can be used to drive types of piles including concrete piles, steel sheet, and pipe piles and even some advanced composite materials sheet piles [9]. The past studies focused on engineering issues such as pile bearing capacity [10-12] and vibrations and settlements transferred to the ground and structure [13-23].
Besides, some researchers begin to study how to improve the penetration rate of the pile in order to speed up the construction progress.

Three major actors play a role in the mechanics of the vibratory sinking process: (i) the pile to be driven, (ii) the selected driving system, and (iii) the imposed soil conditions. The pile can be fully described by its material and geometry. The vibratory driving system can be assessed based on its specifications and operational range. Soil conditions are usually characterized by means of standard investigation tools such as SPT, borings, and laboratory tests. Obviously, vibratory pile driving is a very complex process and the penetration rate of pile is affected by the large number of variables associated with these three actors. Significant previous work has been completed in some areas, including interpretation of field records, use of simplified theoretical and numerical models, and use of laboratory models.

Viking [5] conducted the full-scale tests on steel sheet piles driven by a leader-mounted system in relatively homogeneous soil conditions that mainly consisted of silty sand and sand. Curves of the penetration rate of piles with and 
TABLE 1: Factor classification.

\begin{tabular}{|c|c|c|c|}
\hline Series & Type & Explanation & Related factors \\
\hline$a$ & Driving force & The force vibratory hammer transfers to pile. & $\begin{array}{l}\text { Properties of vibratory hammers including the } \\
\text { moment of inertia and the angular frequency. }\end{array}$ \\
\hline$b$ & Resistances & $\begin{array}{c}\text { Concluding shaft resistance, toe resistance and } \\
\text { clutch friction. }\end{array}$ & Soil conditions and the size of pile-soil interface. \\
\hline$c$ & Vibratory amplitude & $\begin{array}{l}\text { Be related with the time of liquefaction and } \\
\text { degradation of surrounding soils. }\end{array}$ & $\begin{array}{l}\text { Properties of vibratory hammers and piles, as well } \\
\text { as soil conditions. }\end{array}$ \\
\hline$d$ & Energy consumption & $\begin{array}{c}\text { Generating due to the pile lateral vibration during } \\
\text { the sinking process. }\end{array}$ & $\begin{array}{l}\text { Length and sectional properties of piles, as well as } \\
\text { soil conditions. }\end{array}$ \\
\hline$e$ & $\begin{array}{l}\text { Speeding up at the } \\
\text { beginning }\end{array}$ & $\begin{array}{l}\text { The time of vibratory driving system working } \\
\text { from start to run stable. }\end{array}$ & $\begin{array}{l}\text { The performance of vibratory driving systems and } \\
\text { the skill of operators. }\end{array}$ \\
\hline$f$ & Pile plumbness keeping & $\begin{array}{l}\text { Operators generally reduce penetration rate for } \\
\text { keeping pile plumbness. }\end{array}$ & $\begin{array}{l}\text { The type of vibratory driving systems and the type } \\
\text { of piles, as well as the skill of operators. }\end{array}$ \\
\hline$g$ & Slowing down at the end & $\begin{array}{l}\text { At the end of penetration operators often } \\
\text { consciously reduce penetration rate. }\end{array}$ & Mainly refer to short piles driven in soft soils. \\
\hline
\end{tabular}

without clutch and penetration depth were illustrated and the reason for the slow penetration rate in initial depth was explained. Whenham et al. [24, 25] established the relationship between the penetration rate and energy consumption in sinking process through the numerous full-scale tests on large size sheet piles. Lee et al. [26] conducted the full-scale tests on steel sheet piles driven by a free-hanging system in soils stratified by silty sand and plasticity clay. The measured penetration rate was compared with the predicted value derived from a developed program and the GRL-WEAP.

Feng and Deschamps [27] used the finite difference program, FLAC, to simulate the pile-hammer-soil system in which several variables including soil strength, pile-soil interface friction angle, lateral earth pressure coefficient, hammer operating frequency, bias weight, hammer centrifugal force, and pile embedment were examined to assess their relative importance in pile penetration rate.

Through the laboratory tests in dry cohesionless soils, Rodger and Littlejohn [28] investigated the slow vibratory driving technique and found that the penetration rate increased with the displacement amplitude and surcharge force of vibration. O'Neill et al. [29] used a large scale laboratory testing system to investigate the influence of the soil parameters including particle size and relative density and in situ stress conditions as well as the vibratory hammer consisting of bias weight, eccentric moment, and the frequency on the penetration rate of piles and found that the relative density of soil has the greatest influence on the rate and the optimum frequency is $20 \mathrm{~Hz}$. Based on the same test, Vipulanandan et al. [30] established a link between bearing capacity and penetration rate of piles and compared the results with the formulas proposed by Schmid and Davission. Chen et al. [31] used small scale tests to simulate the pile vibratory driven in saturated sands at high frequencies and found that the higher frequencies caused the saturated sand lower values of the liquefaction strength, which may lead to a decreased penetration time.

Even so, there are few comprehensive studies on the influence of the penetration rate of piles driven by vibratory driving technique. In this study, factors directly affecting the penetration rate of piles are summarized and classified into seven factors from the mechanism and engineering practice of the pile driving. Field tests on steel sheet piles driven by vibratory driving technique in different soil conditions are conducted. The penetration rate of three different sheet pile types having up to four different lengths installed using two different vibratory driving systems are documented. How these seven direct acting factors affect the penetration rate of the pile through the three actors of vibratory sinking process is studied.

\section{Factor Classification}

Factors directly affecting the penetration rate of piles driven by vibratory driving technique are summarized and classified from the mechanism and engineering practice of the pile driving, as shown in Table 1.

Factor $(a)$ through factor $(d)$ come from the kinematic characteristic of vibratory pile sinking process, and the first three factors are the main factors affecting the penetration rate of piles, and factor $(d)$ has obvious effect on long piles driven in difficult soil conditions. Factor $(e)$ through factor $(g)$ are derived from engineering practice of vibratory pile driving in construction, factors $(e)$ and $(g)$ have prominent effect on piles penetrated in soft soil conditions, and factor $(f)$ has obvious effect on long piles or piles driven with clutch.

\section{Field Tests}

In order to find out how those seven direct acting factors affect the penetration rate of the pile through the three actors of vibratory sinking process, field tests on steel sheet piles driven by vibratory drivers are conducted at a high speed rail way construction site, which are located in the city of Qingdao, Shandong province.

3.1. Piles. U-type Larssen steel sheet piles manufactured by SUMITOMO METALS are used in tests and their shapes are shown in Figure 1. 
TABLE 2: Dimensions and sectional properties for steel sheet piles chosen in test.

\begin{tabular}{lccccccccc}
\hline Type & $\begin{array}{c}W \\
\mathrm{~mm}\end{array}$ & $\begin{array}{c}H \\
\mathrm{~mm}\end{array}$ & $\begin{array}{c}t \\
\mathrm{~mm}\end{array}$ & $\begin{array}{c}A \\
\mathrm{~cm}^{2}\end{array}$ & $\begin{array}{c}C \\
\mathrm{~cm}\end{array}$ & $\begin{array}{c}I_{x} \\
\mathrm{~cm}^{4}\end{array}$ & $\begin{array}{c}W_{x} \\
\mathrm{~cm}^{3}\end{array}$ & $\begin{array}{c}r \\
\mathrm{~cm}\end{array}$ & $\begin{array}{c}m \\
\mathrm{~kg} / \mathrm{m}\end{array}$ \\
\hline Larssen-III & 400 & 125 & 13.0 & 76.42 & 137.85 & 2,220 & 223 & 5.39 & 60.0 \\
Larssen-IV & 400 & 170 & 15.5 & 96.99 & 154.80 & 4,670 & 362 & 6.94 \\
Larssen-V & 500 & 200 & 24.3 & 133.8 & 175.13 & 7,960 & 520 & 7.71 & 105 \\
\hline
\end{tabular}

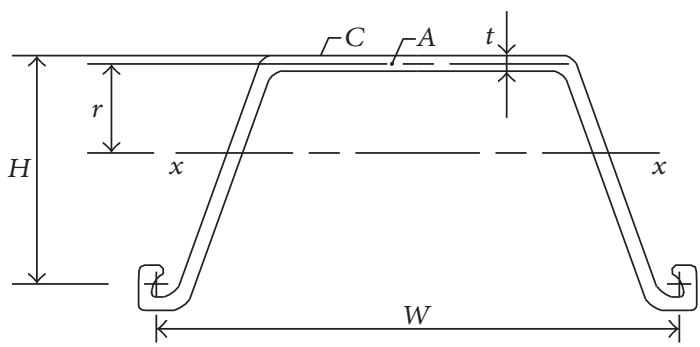

FIGURE 1: The shapes of U-type Larssen steel sheet piles.

Three different types of piles including Larssen-III, Larssen-IV, and Larssen-V are chosen and their basic data of sectional properties including the width, height, thickness, area, perimeter, moment of inertia, section modulus, radius of gyration, and unit mass are shown in Table 2. Besides, four different long piles of Larssen-IV consisting of $3 \mathrm{~m}, 6 \mathrm{~m}, 9 \mathrm{~m}$, and $12 \mathrm{~m}$ are adopted. Each pile is marked every half a meter.

Pile is regarded as a rigid body, and penetration rate in pile head and toe is consistent. Viking and Bodare [32] used $T / 4>2 t_{n}$ as a rule of thumb, when defining a system with a vibrator and a model pile of length $L$ as a rigid body, where $T$ is the time period of the vibration and $t_{n}$ is the time taken for a stress wave to travel back and forth. $t_{n}$ can be computed as $2 L / c$, where $L$ is the pile length in which the maximum value in tests is $12 \mathrm{~m}$ and $c$ is the stress wave velocity whose value is about $5100 \mathrm{~m} / \mathrm{s}$ for steel. For the vibration system of the instrumented test, $T$ was $0.02 \mathrm{sec}$, and $t_{n}$ was computed as $0.0047 \mathrm{sec}$, so it can be confirmed for the proof test.

3.2. Vibratory Driving Systems. Two different types of excavator driving systems and a free-hanging system are chosen in test. Excavator driving system is the modified excavator equipped with a hydraulic vibratory hammer instead of the bucket; besides, in order to finish driving long piles, the excavator often extends its arm length and increases its balance weight, as shown in Figure 1. EX450 excavator with CF330 hammer (hereafter referred to as EX450) and EX470 excavator with CF350 hammer (hereafter referred to as EX470) are adopted in tests. The free-hanging system consists of a crawler crane and an electrical vibratory hammer DZ120A (see Figure 2).

No matter the excavator driving system or the freehanging system, the core part is a vibratory hammer which consists of three main parts: bias mass, exciter, and clamp, and the vertical vibration force is generated by a pair of unbalanced rotating masses located in the exciter. Basic data

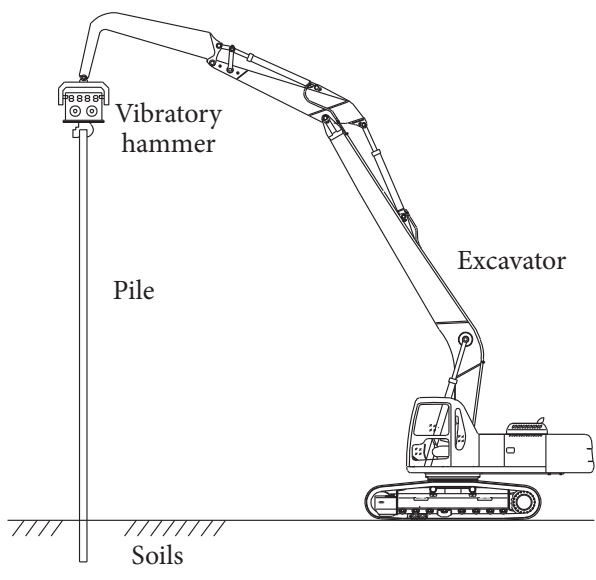

(a) Excavator driving system

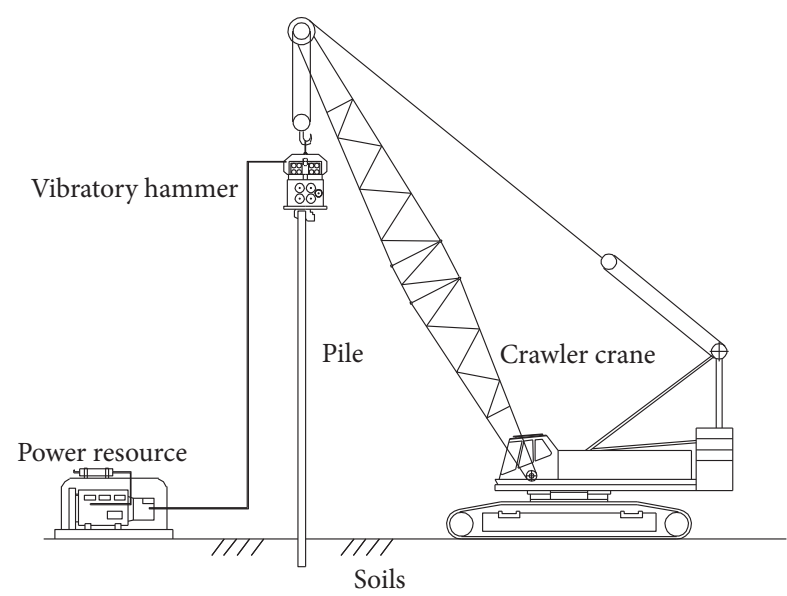

(b) Free-hanging system

FIgURE 2: Two vibratory-driver systems.

of three vibratory hammers in different driving systems are shown in Table 3.

3.3. Soil Conditions. Three sites near the railway are chosen, site 1 close to site 2, and site 3 is about two kilometers away from others. The soil conditions encountered in site 1 and site 2 generally consist of backfill, fine sand, silty clay with varying amounts of marine shell fragments, and coarse sand. What in site 3 generally consists of backfill, muddy silty clay, clay, gravelly sand, and pelitic siltstone. The thickness of every soil layer and $N$-values with depths in test sites are measured, as shown in Figure 3. The water table is two meters below the ground surface. 


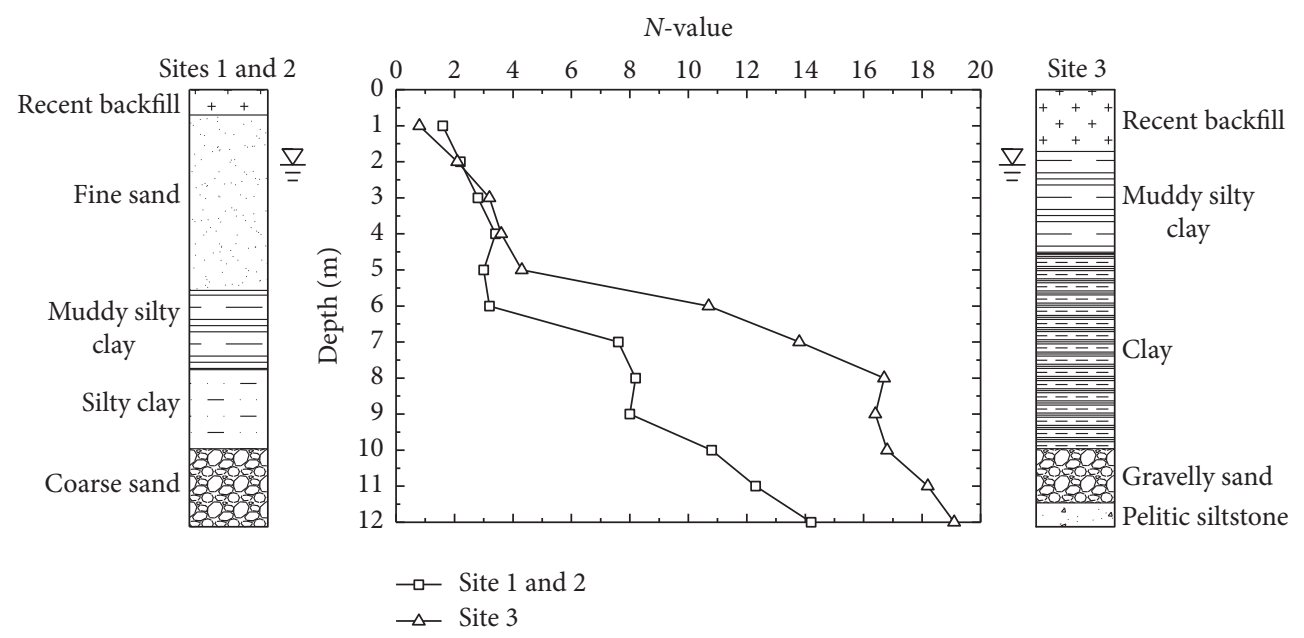

FIGURE 3: Soil layers and $N$-value versus depth.

TABLE 3: Parameters of vibratory hammers.

\begin{tabular}{lccc}
\hline Type & CF330 & CF350 & DZ120A \\
\hline Rated power (kW) & 90 & 90 & 120 \\
Frequency (rpm) & 3500 & 3500 & 1050 \\
Force (kN) & 500 & 550 & 658 \\
Eccentric moment (kgm) & 3.71 & 4.08 & 53.40 \\
Amplitude (mm) & 4.37 & 4.70 & 11.6 \\
Dynamic mass (kg) & 1100 & 1250 & 5500 \\
Static mass (kg) & 1550 & 1550 & 1500 \\
\hline
\end{tabular}

3.4. Test Schedule. The process of vibratory pile driving can be concluded that, firstly, the vibratory driving equipment clamps and lifts a pile, after adjusting the plumbness of the pile, and drives it into the soil through the vibration of the vibratory hammer.

Stopwatches with the precision of $0.01 \mathrm{~s}$ are used to record penetration time, and the time per half one meter of pile penetration is recorded; besides, a camera is fixed to record the pile sinking process for checking in later. The penetration rate of the pile with penetration depth can be calculated from the penetration time.

There are thirteen series of tests that are conducted, and each series have three piles driven in parallel. The classification is shown in Table 4.

\section{Test Results and Analyses}

4.1. Sinking Process. Figure 4 displays penetration rates of piles in series A through $\mathrm{D}$ with penetration depth, which represent different pile lengths. In the same series, the curves of three piles are similar, and the mean value is calculated to represent the test result.

In general, the soil strength increases with the depth, and the penetration resistance of piles is gradually increasing. Taking the pile with a length of $12 \mathrm{~m}$ as an example, the development of penetration rate with the penetrating depth can be divided into three stages which include (i) increasing phase, (ii) stable phase, and (iii) decreasing phase. At the beginning, the penetration rate increases with penetration depth due to the low soil resistance and the normalization process of the vibrator hammer from starting period. And, then, the penetration rate keeps at a constant approximatively as the soil resistance is remaining stable and the vibrator hammer is operating at a normal state. Finally, the penetration rate decreases significantly with penetration depth due to the remarkable increase in the pile shaft and pile toe resistance when the pile encounters the coarse sands layer.

4.2. Influence of Piles. The penetration rates of three different sheet pile types having up to four different lengths driven with or without clutch are documented.

4.2.1. Pile Length. Figure 5 shows penetration rates of different long piles changing with penetration depth. When the penetration depth is less than $3 \mathrm{~m}$, the rate of $3 \mathrm{~m}$ long pile is smaller than others due to the influence of the factor (g). When penetration depth lies between $4 \mathrm{~m}$ and $6 \mathrm{~m}$, the average rates of $6 \mathrm{~m}, 9 \mathrm{~m}$, and $12 \mathrm{~m}$ long piles are $616.3 \mathrm{~mm} / \mathrm{s}$, $557.6 \mathrm{~mm} / \mathrm{s}$, and $460.7 \mathrm{~mm} / \mathrm{s}$; affected by factors $(c),(d)$, and $(f)$, the rate of $12 \mathrm{~m}$ long pile is $82.6 \%$ of $9 \mathrm{~m}$ long pile. When penetration depth exceeds $6 \mathrm{~m}$, the rates of both $9 \mathrm{~m}$ and $12 \mathrm{~m}$ will slow down affected by factor $(b)$.

Long piles are heavier than short piles; affected by factor (c), they have smaller vibratory amplitude than short ones, which will cause penetration rate of long piles slowing down. Besides, according to factors $(d)$ and $(f)$, because of possessing long length above the ground, long piles have more energy consumption and difficulty in keeping plumbness than short piles in sinking process, and both of them will reduce the penetration rate of long piles.

4.2.2. Pile Type. There are many different types of $U$ section steel sheet piles, but most of them used in China are LarssenIII, Larssen-IV, and Larssen-V. According to Table 2, different types have different dimensions and sectional properties. 
TABLE 4: Summary of field tests.

\begin{tabular}{|c|c|c|c|c|c|c|c|}
\hline Series & Test site & Pile type & Pile length (m) & Clutch & Driving system & Operator & Penetration time (s) \\
\hline$\overline{\mathrm{A}}$ & $1 \#$ & Larssen-IV & 3 & Without & EX450 & Skilled & 10.48 \\
\hline B & $1 \#$ & Larssen-IV & 6 & Without & EX450 & Skilled & 14.08 \\
\hline $\mathrm{C}$ & $1 \#$ & Larssen-IV & 9 & Without & EX450 & Skilled & 19.37 \\
\hline $\mathrm{D}$ & $1 \#$ & Larssen-IV & 12 & Without & EX450 & Skilled & 44.36 \\
\hline $\mathrm{F}$ & $1 \#$ & Larssen-V & 9 & Without & EX450 & Skilled & 23.12 \\
\hline G & $1 \#$ & Larssen-III & 9 & Without & EX450 & Skilled & 18.59 \\
\hline $\mathrm{H}$ & $1 \#$ & Larssen-IV & 9 & With & EX450 & Skilled & 37.46 \\
\hline J & $2 \#$ & Larssen-IV & 12 & Without & EX450 & Skilled & 34.26 \\
\hline K & $2 \#$ & Larssen-IV & 12 & Without & EX470 & Skilled & 28.72 \\
\hline $\mathrm{L}$ & $2 \#$ & Larssen-IV & 12 & Without & EX450 & New & 40.22 \\
\hline Q & $3 \#$ & Larssen-IV & 12 & Without & EX450 & Skilled & 479.41 \\
\hline $\mathrm{R}$ & $3 \#$ & Larssen-IV & 12 & Without & EX470 & Skilled & 644.11 \\
\hline S & $3 \#$ & Larssen-IV & 12 & Without & Free-hanging & Skilled & 672.41 \\
\hline
\end{tabular}

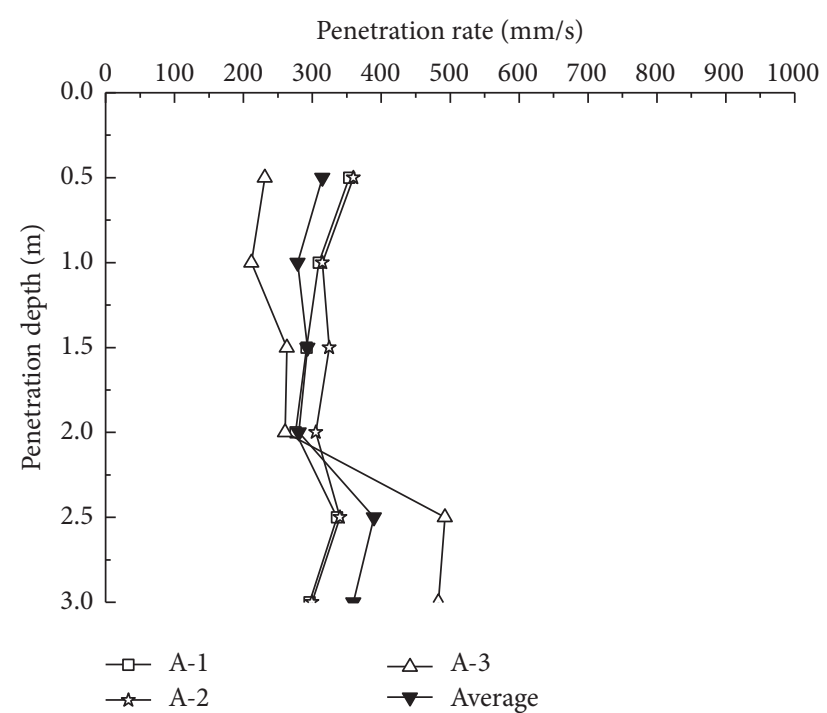

(a)

Penetration rate $(\mathrm{mm} / \mathrm{s})$

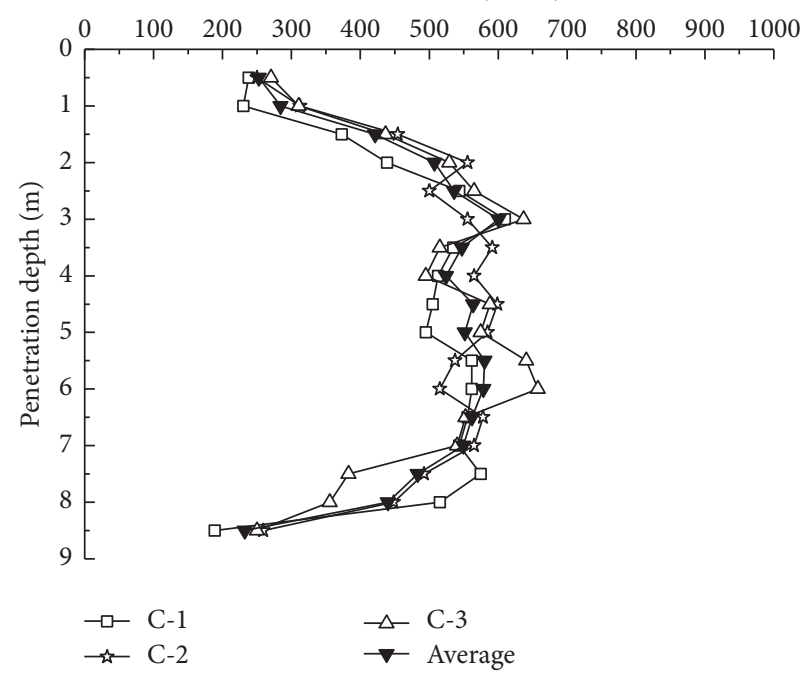

(c)

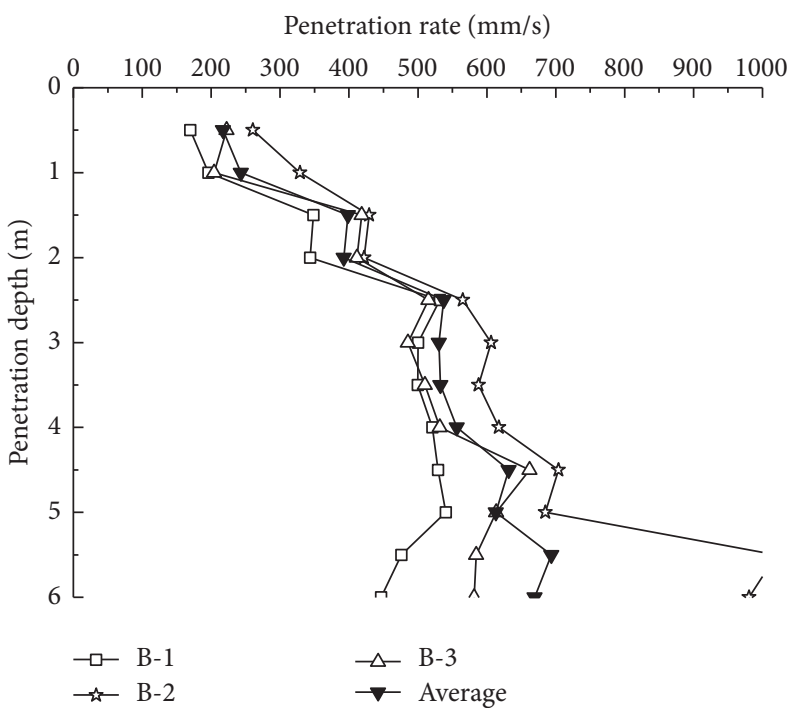

(b)

Penetration rate $(\mathrm{mm} / \mathrm{s})$

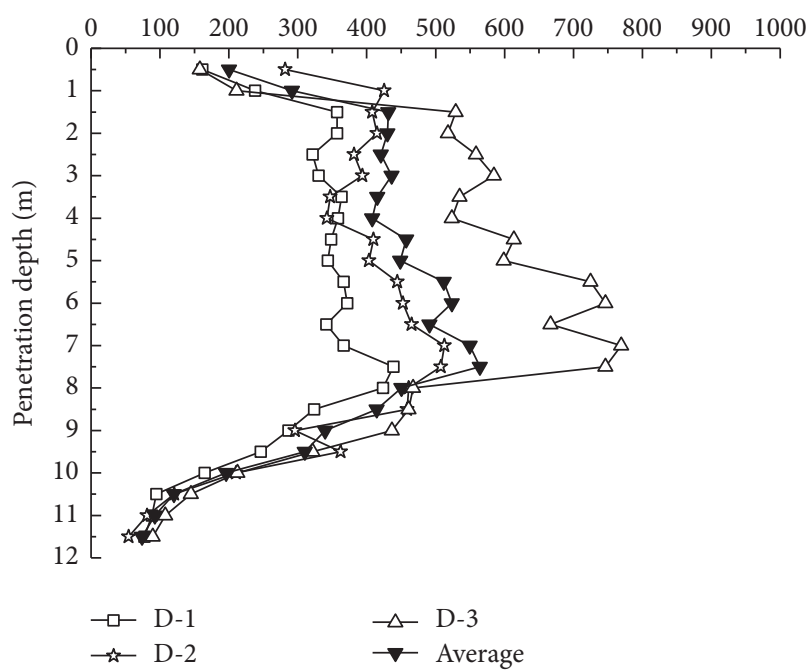

(d)

Figure 4: Penetration rate of piles from series A to series $\mathrm{D}$ versus penetration depth: (a) pile length $=3 \mathrm{~m}$, (b) pile length $=6 \mathrm{~m}$, (c) pile length $=9 \mathrm{~m}$, and $(\mathrm{d})$ pile length $=12 \mathrm{~m}$. 


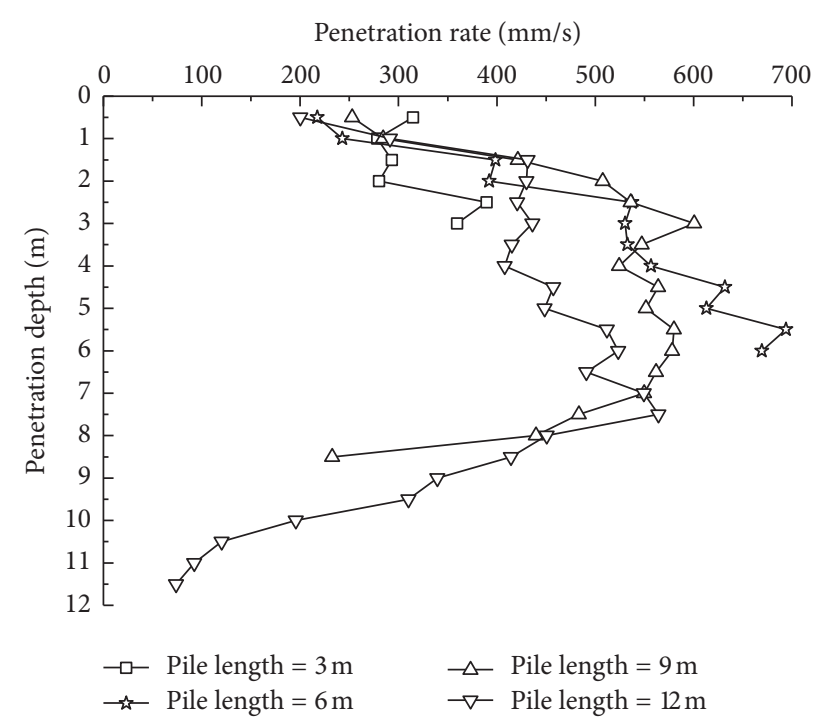

Figure 5: Penetration rate of piles with different lengths versus penetration depth.

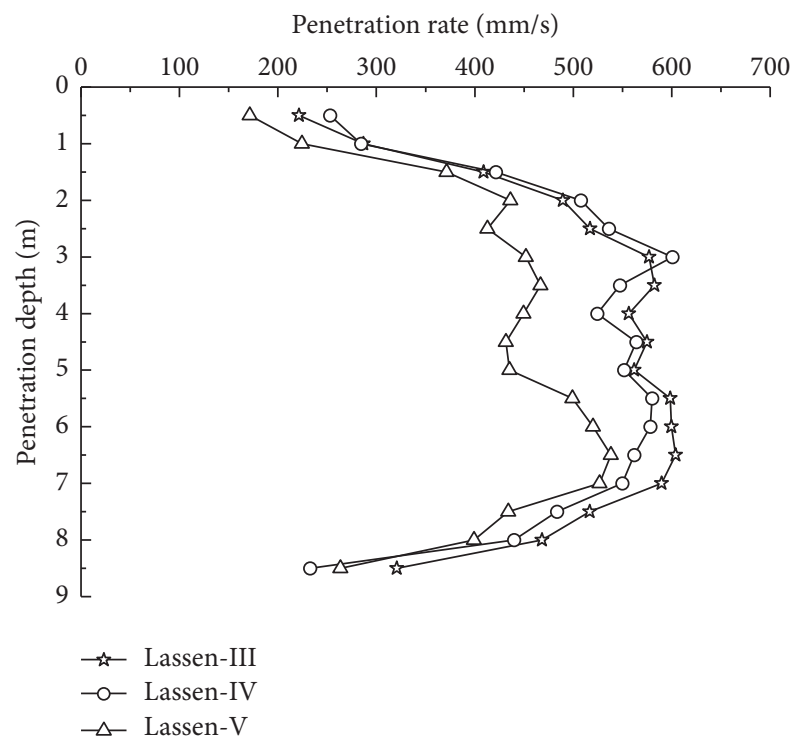

Figure 6: Penetration rate of piles with different types versus penetration depth.

Figure 6 shows penetration rates of different type piles changing with penetration depth. It is found that the shape of each curve is similar, which demonstrates that all types conform with the law of penetration rate of pile changing with penetration depth. From Larssen-III to Larssen-V, their dimensions and sectional properties, such as the weight, the sectional area, the perimeter, and the radius of gyration, are gradually increasing, affected by factors $(b)$ through $(d)$; at the stable phase, their penetration rates are gradually decreasing. Their average rates at depth of $4 \mathrm{~m}$ to $6 \mathrm{~m}$ are $579.0 \mathrm{~mm} / \mathrm{s}, 557.6 \mathrm{~mm} / \mathrm{s}$, and $467.1 \mathrm{~mm} / \mathrm{s}$, respectively; the rates of Larssen-III and Larssen-V are $103.8 \%$ and $83.8 \%$ of Larssen-IV.

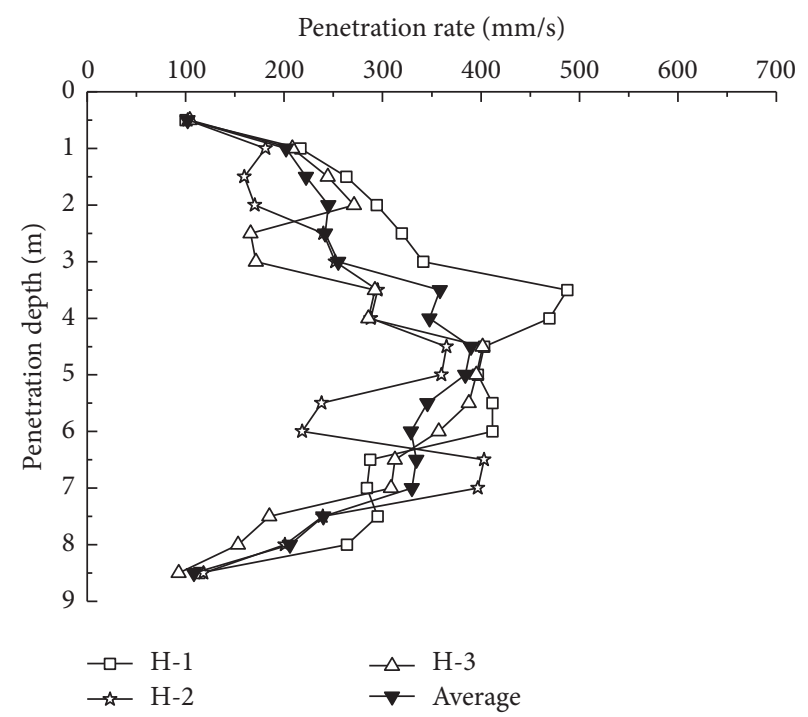

FIgURE 7: Penetration rate of piles in series $H$ versus penetration depth.

Like the results of the pile length, affected by factor $(c)$, the pile with heavy weight will slow down penetration rate due to the small vibratory amplitude. The pile with large sectional area and perimeter increases the toe and shaft resistance, respectively, which will decrease the penetration rate affected by factor $(b)$. Lee et al. $[33,34]$ have studied that piles with large radius of gyration will increase energy consumption for a large lateral vibration in sinking process, which will slow down penetration rate too, according to factor $(d)$.

4.2.3. Clutch. As we all know, steel sheet piles are generally used as retaining wall or cofferdam in construction by joining together one by one through interlock joint. Piles in series $\mathrm{H}$ were firstly interlocked together with the near one which had been embedded in earth and then are penetrated into the soil. Figure 7 displays the penetration rate and penetration depth curves of these piles. In comparison with Figure 4(c) which illustrates the results of those piles without clutch, it is found that curves in Figure 7 have much more differences between each other because of the existing of the clutch.

Figure 8 sketches two relationship curves of penetration rate and penetration depth, respectively, representing piles with clutch and without clutch. It is clearly found that penetration rates for the case "with clutch" are smaller than those of "without clutch" in whole sinking process, which agrees with Lee et al. [26]. The average rate of pile with clutch between $4 \mathrm{~m}$ and $6 \mathrm{~m}$ is $359.1 \mathrm{~mm} / \mathrm{s}$, and the value is only $64.4 \%$ of the pile without clutch. The reasons are summarized as follows: (i) clutch limits the vibratory amplitudes of the pile (factor $(c)$ ), (ii) interlock friction of two adjacent piles increases the resistance, and (iii) soil-interlock friction in clutch increases the resistance too (factor $(b)$ ).

In conclusion, piles with different lengths and types driven with or without clutch have different penetration rates almost in the whole sinking process. Comparing the average penetration rate of piles at the stable phase in Figures 5, 6, and 


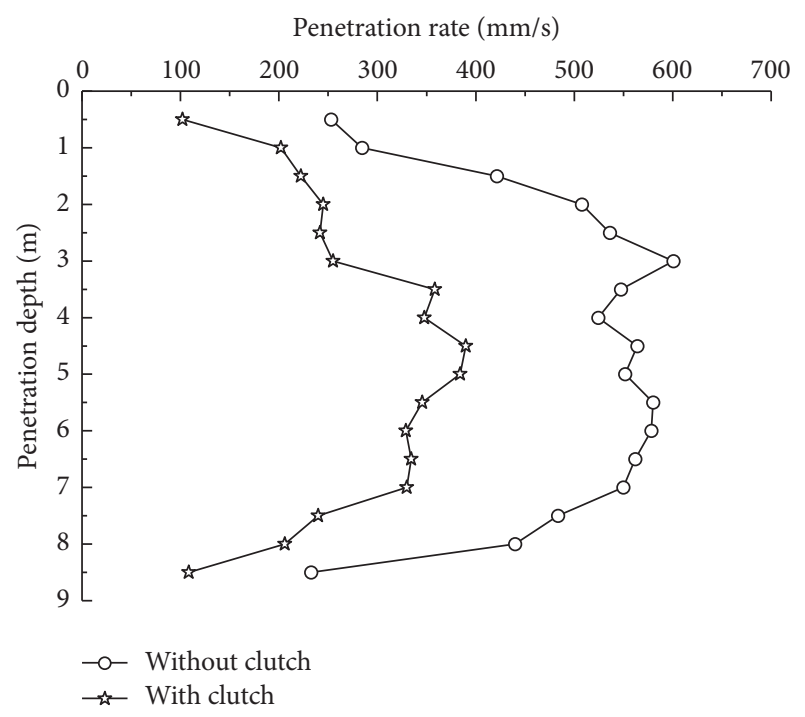

FIgURE 8: Penetration rate of piles with/without clutch versus penetration depth.

8 , it can be found that the clutch has the most dramatic effect on the penetration rate, followed by the pile length and type.

4.3. Influence of Vibratory Driving Systems. As mentioned earlier, all piles in site 1 and site 2 are driven by excavator driving systems consisting of EX450 and EX470. In site 3, except the two excavator driving systems, a free-hanging system composed of an electricity vibratory hammer and a crawler crane is also chosen.

4.3.1. Skill of Operator. Piles in series J and series L both are driven by EX450, but the equipment operator is different, the former is operated by a skilled operator, and the latter is operated by a new one.

Figure 9 displays the penetration rate and penetration depth curves of piles in series J and series L, and it is found that the curves in Figure 9(b) are lightly messier than those in Figure 9(a). In excavator driving system, power of vibratory hammer is supplied by excavator engine as well as all kinds of motion of excavator during the sinking process. Because of the complexity of the cooperative working between the excavator and the vibratory hammer, operators should be well trained and be familiar with the composite system.

4.3.2. Driving Force. The main difference between the EX450 and the EX470 is the driving force they transfer to the pile, and the value is $500 \mathrm{KN}$ and $550 \mathrm{KN}$, respectively. Figure 10 shows the penetration rate of piles driven in site 2 changing with penetration depth. The average rates of piles driven by EX450 and EX470 at depth of last three meters are $265.1 \mathrm{~mm} / \mathrm{s}$ and $376.3 \mathrm{~mm} / \mathrm{s}$, respectively.

Affected by factor $(a)$, penetration rate of pile driven by EX470 is faster than those driven by EX450 in later stage of the whole sinking process, but not obviously in early stage. The reason is that, at early sinking process, resistance pile encountered is small, and even a small driving force can

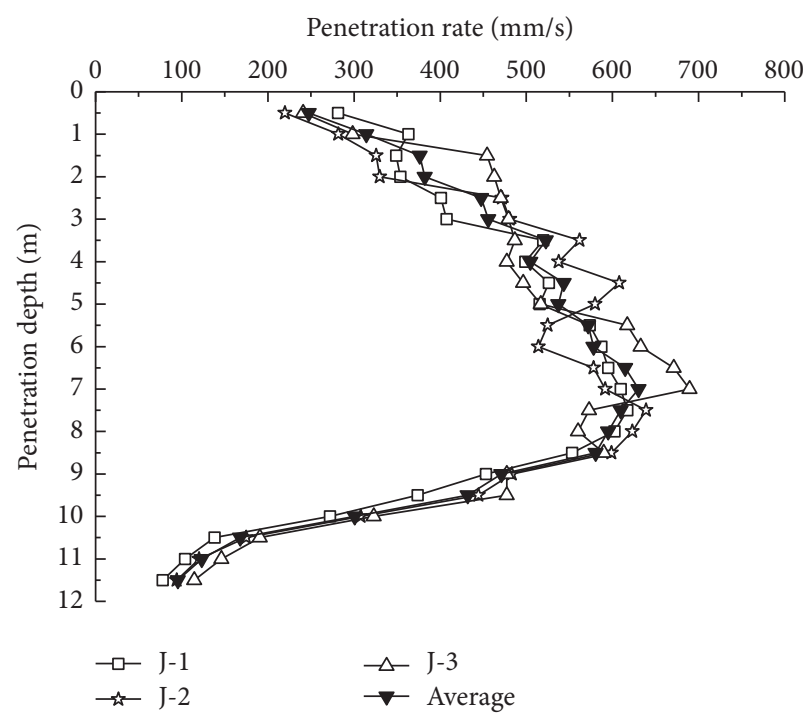

(a)

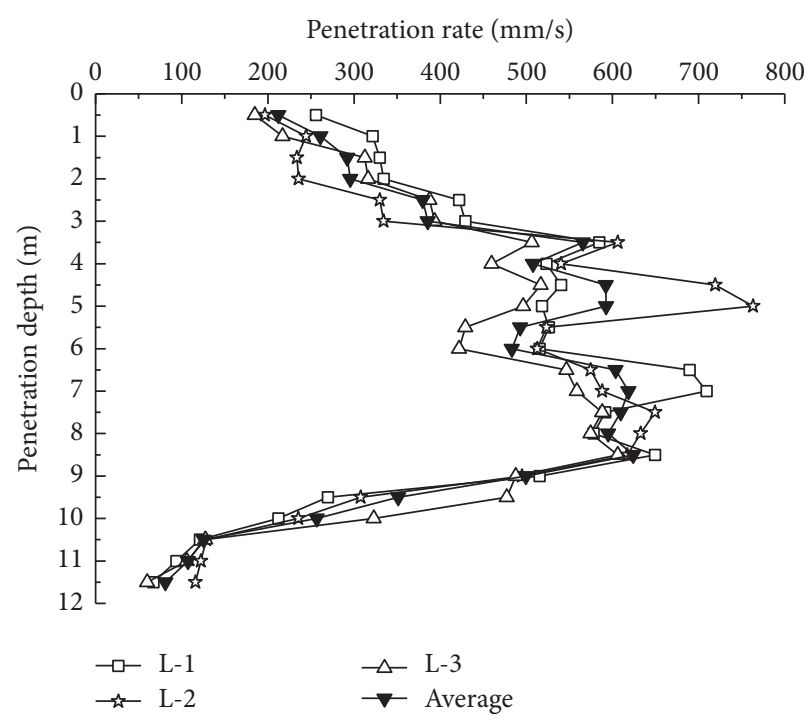

(b)

FIGURE 9: Penetration rate of piles in series J and series L versus penetration depth: (a) operated by the skilled operator. (b) Operated by the new operator.

make an equal penetration rate of the pile with the big one. But, following the penetration depth increase, penetration resistance becomes bigger and bigger, which will gradually lead to differences of penetration rate of piles installed by different driving force. It can be summed up that increasing driving forces can dramatically increase penetration rate in stiff soils, but not effective in soft soils. In addition, from Figure 10, it can be found that the rate of pile driven by the new operator is smaller than that driven by the skilled one affected by factor $(f)$.

4.3.3. Driving System. In site 3, piles in series $\mathrm{Q}$ and series $\mathrm{R}$ are penetrated by EX450 and EX470, respectively, and their maximum penetration depth is $9 \mathrm{~m}$ and $10 \mathrm{~m}$, which can not 


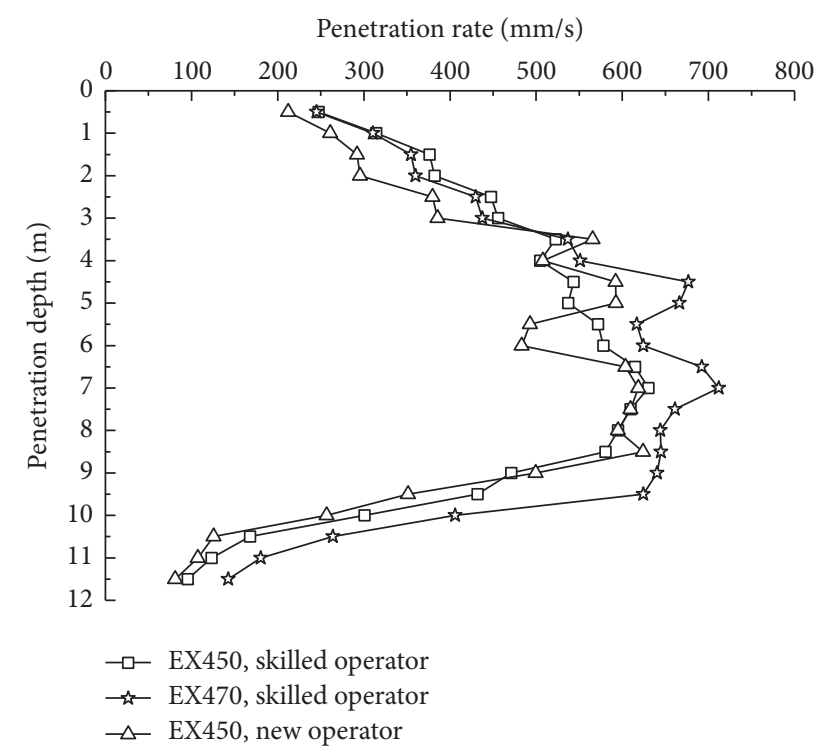

FIGURE 10: Penetration rate of piles driven in site 2 versus penetration depth.

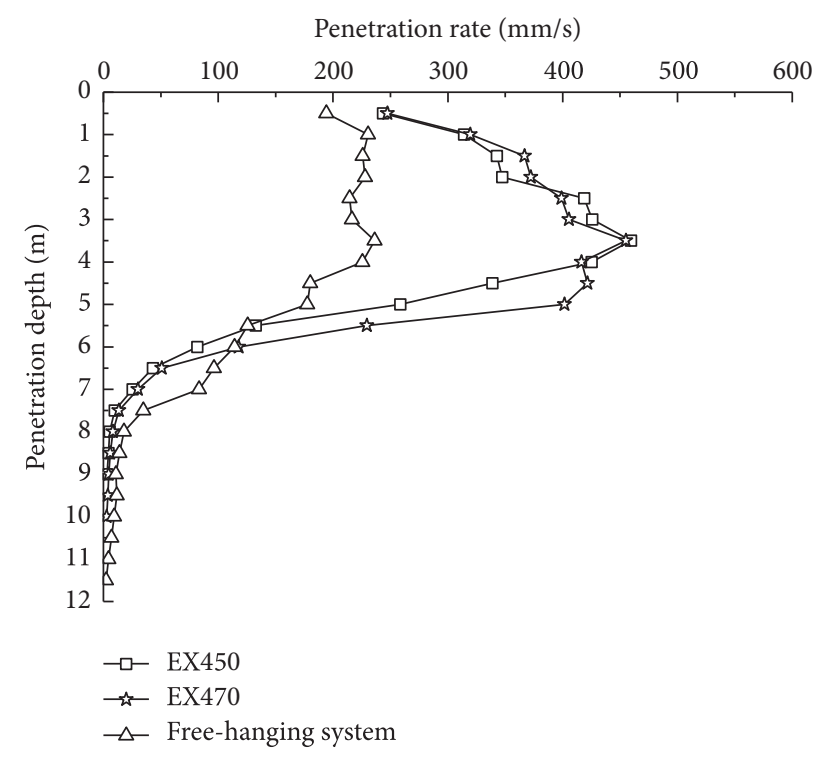

FIGURE 11: Penetration rate of piles driven in site 3 versus penetration depth.

reach to the design depth. Piles in series $S$ are driven by the free-hanging system, and the depth of these piles reaches the design depth $11.5 \mathrm{~m}$, and all of these test results are shown in Figure 11.

The curves of penetration rate of piles driven by different systems and penetration depth are slightly different. There is no increasing phase at the beginning of the sinking process to the free-hanging system, because, in free-hanging system, vibratory hammer is independent of the crawler crane, and the crawler crane is only used as a suspension equipment to the vibratory hammer in vertical direction. The average

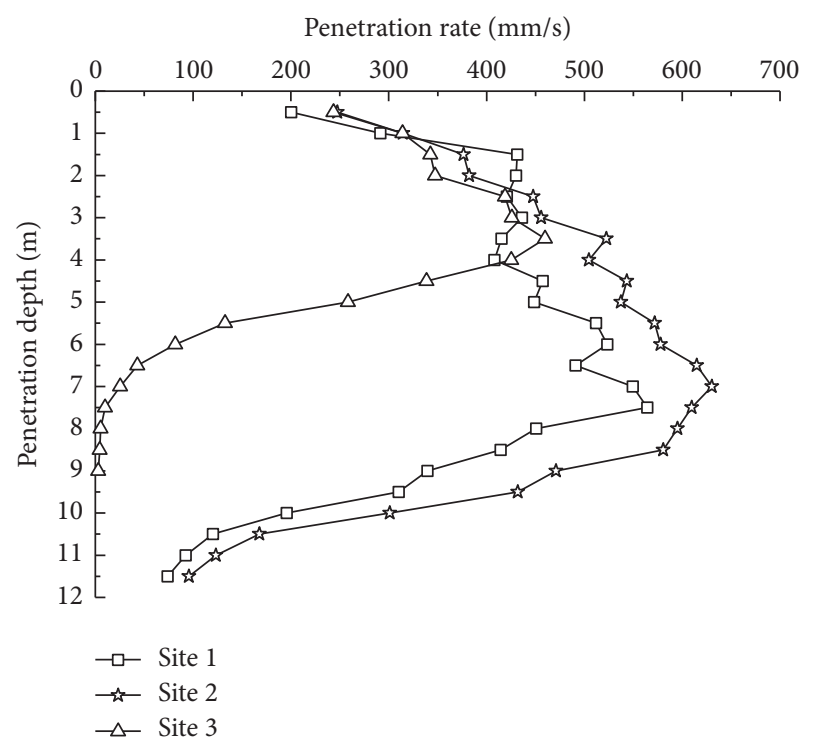

FIGURE 12: Penetration rate of piles driven in different sites versus penetration depth.

rates of piles driven by EX450 and EX470 and the freehanging system at penetration depth between $7 \mathrm{~m}$ and $9 \mathrm{~m}$ are $15.3 \mathrm{~mm} / \mathrm{s}, 18.8 \mathrm{~mm} / \mathrm{s}$, and $42.9 \mathrm{~mm} / \mathrm{s}$, respectively; the rate of piles driven by the free-hanging system is about three times faster than that by the excavator driving systems.

Driving force and vibratory amplitude play important roles in penetration rate of piles driven by vibratory installation. From Table 3, it can be seen that although the driving force of the free-hanging system is slightly larger than the excavator driving system, for possessing an obviously big vibratory amplitude, the penetration rate of piles driven by the free-hanging system is prominently faster than that by the excavator driving system.

4.4. Influence of Soil Conditions. Results of penetration rate of piles driven by EX450 in different sites versus penetration depth are shown in Figure 12. At the beginning of the penetration, rates of all piles are about $500 \mathrm{~mm} / \mathrm{s}$, but, following the penetration depth increase, the value gradually decreases. In upper soils no matter the fine sand in site 1 and site 2 or the muddy silty clay in site 3 , their resistance is likely and low, but, in deep soils, the resistance of the silty clay in site 1 and site 2 as well as clay in site 3 is very big. According to factor (b), the penetration rates of piles decrease with the penetration depth.

Comparing the penetration rates of piles driven in different sites, when penetration depth exceeds 4 meters, the penetration rate of piles sharply decreases until zero at the depth of 9 meters in site 3 and the value is significantly lower than those in site 1 and site 2 at the equal depth in this stage. The average rates of piles driven in site 1 to site 3 at penetration depth between $7 \mathrm{~m}$ and $9 \mathrm{~m}$ are $468.2 \mathrm{~mm} / \mathrm{s}, 583.7 \mathrm{~mm} / \mathrm{s}$, and $15.3 \mathrm{~mm} / \mathrm{s}$, respectively. Rates of piles driven in site 3 are far slower than those in site 1 and site 2 , and the reason is that the resistance of clay in site 3 is much bigger than the resistance 
of muddy silty clay in site 1 and site 2 , which will obviously slow down penetration rate. In general, saturated sands and muddy silty clay are more suitable than the clay for using the vibratory driving technique.

In addition, although a big power vibratory hammer can drive the pile to design depth in site 3 , the average penetration rate of last three meters is only $6.0 \mathrm{~mm} / \mathrm{s}$ which can not meet requirements of construction. In these conditions, guiding hole by twist drill and water jetting [35] by hydraulic giant are good for vibratory pile driving.

\section{Conclusion}

In this study, factors directly affecting the penetration rate of piles are summarized and classified into seven factors from the mechanism and engineering practice of the pile driving. Field tests on steel sheet piles driven by vibratory driving technique in different soil conditions are conducted. The penetration rates of three different sheet pile types having up to four different lengths installed using two different vibratory driving systems are documented. How these seven direct acting factors affect the penetration rate of the pile through the three actors of vibratory sinking process is studied. Main conclusions are as follows.

(1) From the mechanism and engineering practice of the vibratory pile driving, factors directly affecting the penetration rate of piles installed by vibratory driving technique are summarized and classified into seven factors which include (a) driving force, $(b)$ resistance, $(c)$ vibratory amplitude, $(d)$ energy consumption, $(e)$ speeding up at the beginning, $(f)$ pile plumbness keeping, and $(g)$ the slowing down at the end.

(2) Mainly affected by factors $(b)$ through $(d)$ and factor $(f)$, piles with different lengths and types driven with or without clutch have different penetration rates. The long pile, large-sized pile, and pile driven with clutch have lower penetration rate than those opposite ones. According to contrastive analysis, the clutch has the most dramatic effect on the penetration rate, followed by the pile length and type.

(3) The performance of vibratory driving system has significant influence on pile penetration rate according to factors $(a)$ and $(c)$. Increasing either the driving force or vibratory amplitude can speed up the penetration rate, especially if the two improvements are adopted at the same time. In addition, the skill of operators also affects the penetration rate of piles driven by vibratory technique.

(4) Penetration rates of piles driven in different soil conditions are inconsistently affected by factor $(b)$. Penetration rates of piles driven in fine sand and muddy silty clay are nearly uniform and dramatically faster than in clay. In some difficult soil conditions, guiding hole by twist drill and water jetting by hydraulic giant are good for vibratory pile driving.

(5) Affected by those direct acting factors, three actors of vibratory pile driving have influence on penetration rate of the pile in different sinking stages and different extent. Soil conditions determine the application of this technique, which is the most dramatic factor to the penetration rate of the pile. The second factor is the vibratory driving systems which mainly affect the penetration rate of the pile in later sinking process, and the last factor is the property of the pile.

\section{Conflicts of Interest}

The authors declare that they have no conflicts of interest.

\section{Acknowledgments}

The authors would like to acknowledge the financial support provided by the National Natural Science Foundation of China under Grant no. 51428901 and Shanghai Municipal Science and Technology Commission under Grant no. 15DZ1204500.

\section{References}

[1] A. Holeyman, "Vibratory driving analysis," in Proceedings of the 6th International Conference on the Application of Stress-Wave Theory to Piles, pp. 479-494, Sao Paulo, Brazil, September 2000.

[2] A. Holeyman and L. Michiels, "Vibratory penetration and flow shearing in granular materials a review of perspectives," in Proceedings of the International Conference on Vibratory Pile Driving and Deep Soil Compaction, pp. 31-52, Pairs, France, September 2006.

[3] A. Holeyman and V. Whenham, "Critical review of the Hypervib1 model to assess pile vibro-drivability," Geotechnical and Geological Engineering, no. 3, pp. 1-19, 2017.

[4] K. Viking, "The vibratory pile installation technique," in Proceedings of the International Conference on Vibratory Pile Driving and Deep Soil Compaction, pp. 65-82, Pairs, France, September 2006.

[5] K. Viking, Vibro-driveability-A field study driven sheet piles in non-cohesive soils [Ph.D. thesis], Royal Institute of Technology, Stockholm, Sweden, 2002.

[6] T. Mayrberger, K. Braun, W. N. Scott, and J. Cologgi, "Vibratory driven piles in cold permafrost," in Proceedings of the Arctic Technology Conference, pp. 1-12, Houston, Tex, USA, December 2012.

[7] T. Mayrberger, K. Braun, W. N. Scott, and J. Cologgi, "The adfreeze strength characteristics of vibratory driven piles," in Proceedings of the 10th International Symposium on Cold Regions Development: Planning for Sustainable Cold Regions, ISCORD 2013, pp. 45-58, Anchorage, Alaska, USA, June 2013.

[8] Y. Tan and S. G. Paikowsky, "Performance of sheet pile wall in peat," Journal of Geotechnical and Geoenvironmental Engineering, vol. 134, no. 4, pp. 445-458, 2008.

[9] G. Boscato, J. T. Mottram, and S. Russo, "Dynamic response of a sheet pile of fiber-reinforced polymer for waterfront barriers," Journal of Composites for Construction, vol. 15, no. 6, pp. 974984, 2011.

[10] E. C. Lamiman and B. Robinson, "Bearing capacity reduction of vibratory installed large diameter pipe piles," in Proceedings of the Geo-Congress, pp. 475-481, ASCE, Atlanta, GA, USA, February 2014.

[11] M. Ghose-Hajra, R. Jensen, and L. Hulliger, "Pile setup and axial capacity gain for driven piles installed using impact hammer versus vibratory system," in Proceedings of the International Foundations Congress and Equipment Expo 2015, IFCEE, pp. 1064-1074, San Antonio, Tex, USA, March 2015.

[12] K. Kelevišius, L. Gabrielaitis, J. Amšiejus, A. Norkus, and Z. Sikora, "Study of bearing capacity of vibratory pile applying acceleration record," Journal of Civil Engineering and Management, vol. 20, no. 1, pp. 142-148, 2014. 
[13] G. A. Athanasopoulos and P. C. Pelekis, "Ground vibrations from sheetpile driving in urban environment: measurements, analysis and effects on buildings and occupants," Soil Dynamics and Earthquake Engineering, vol. 19, no. 5, pp. 371-387, 2000.

[14] H. R. Masoumi, G. Degrande, and G. Lombaert, "Prediction of free field vibrations due to pile driving using a dynamic soilstructure interaction formulation," Soil Dynamics and Earthquake Engineering, vol. 27, no. 2, pp. 126-143, 2007.

[15] H. R. Masoumi and G. Degrande, "Numerical modeling of free field vibrations due to pile driving using a dynamic soilstructure interaction formulation," Journal of Computational and Applied Mathematics, vol. 215, no. 2, pp. 503-511, 2008.

[16] H. R. Masoumi, S. François, and G. Degrande, "A non-linear coupled finite element-boundary element model for the prediction of vibrations due to vibratory and impact pile driving," International Journal for Numerical and Analytical Methods in Geomechanics, vol. 33, no. 2, pp. 245-274, 2009.

[17] E. L. Hajduk, K. C. Bower, T. W. Mays, D. A. Falatok, and T. S. Perkins, "Development of a driven pile ground vibration case history database," in Proceedings of the International Foundation Congress and Equipment Exposition, pp. 351-358, ASCE, Orlando, Fla, USA,, March 2009.

[18] K. R. Massarsch and B. H. Fellenius, "Ground vibrations from pile and sheet pile driving, Part 1-building damage," in Proceedings of the International Conference on Piling and Deep Foundations, pp. 131-139, Stockholm, Sweden, May 2014.

[19] D. S. Liyanapathirana and S. D. Ekanayake, "Application of EPS geofoam in attenuating ground vibrations during vibratory pile driving," Geotextiles and Geomembranes, vol. 44, no. 1, pp. 5969, 2016.

[20] G. John, S. M. Jill-Roboski, and J. F. Richard, "Sheet pile-iduced vibrations at the lurie excavation project," in Proceedings of the Geotechnical Engineering for Transportation Projects, pp. 21302138, Los Angeles, USA, July 2004.

[21] M. R. Svinkin, "Mitigation of soil movements from pile driving," Practice Periodical on Structural Design and Construction, vol. 11, no. 2, pp. 80-85, 2006.

[22] P. Meijers and A. F. Tol, "The Raamsdonksveer sheet pile test observered settlements due to installation of vibratory driven sheet piles," in Proceedings of the International Conference on Vibratory Pile Driving and Deep Soil Compaction, pp. 353-362, Pairs, France, September 2006.

[23] K. P. Mahutka and J. Grabe, "Numerical prediction of settlements and vibrations due to vibratory pile driving using a continuum model," in Proceedings of the International Conference on Vibratory Pile Driving and Deep Soil Compaction, pp. 243-252, Pairs, France, September 2006.

[24] V. Whenham, N. Huybrechts, C. Legrand, M.-P. Bourdouxhe, and A. Shimtt, "Energy consumption during sheet piles vibrodriving: experimental results," in Proceedings of the International Conference on Vibratory Pile Driving and Deep Soil Compaction, pp. 209-218, Pairs, France, September 2006.

[25] V. Whenham and A. Holeyman, "Full scale sheet pile vibrodriving tests," in Proceedings of the 17th International Conference on Soil Mechanics and Geotechnical Engineering, pp. 1354-1357, Alexandria, Egypt, October 2009.

[26] S.-H. Lee, B.-I. Kim, and J.-T. Han, "Prediction of penetration rate of sheet pile installed in sand by vibratory pile driver," KSCE Journal of Civil Engineering, vol. 16, no. 3, pp. 316-324, 2012.

[27] Z. Feng and R. J. Deschamps, "A study of the factors influencing the penetration and capacity of vibratory driven piles," Soils and Foundations, vol. 40, no. 3, pp. 43-54, 2000.
[28] A. A. Rodger and G. S. Littlejohn, "Study of vibratory driving in granular soils," Geotechnique, vol. 30, no. 3, pp. 269-293, 1980.

[29] M. W. O'Neill, C. Vipulanandan, and D. Wong, "Laboratory modeling of vibro-driven piles," Journal of Geotechnical Engineering, vol. 116, no. 8, pp. 1190-1209, 1990.

[30] C. Vipulanandan, D. Wong, and M. W. O’Neill, "Behavior of vibro-driven piles in sand," Journal of Geotechnical Engineering, vol. 116, no. 8, pp. 1211-1230, 1990.

[31] D. J. Chen, L. Z. Chen, and J. G. Zheng, "Experimental study on mechanism of piling with high-frequency vibration," Railway Engineering, vol. 7, pp. 49-51, 2006 (Chinese).

[32] K. Viking and A. Bodare, "Laboratory studies of dynamic shaft resistance response of a vibro-driven model pile in granular soil by varying the relative density," in Proceedings of the 12th European Conference on Soil Mechanics and Geotechnical Engineering, pp. 863-869, Amsterdam, Netherlands, June 1999.

[33] S.-H. Lee and B.-I. I. Kim, "A study on the effect of lateral vibration of sheet piles on vibratory driving force," Journal of the Korean Industry Technology, vol. 8, no. 4, pp. 848-852, 2007 (Korean).

[34] S.-H. Lee, B-.I. I. Kim, and Z.-C. Kim, "Parameteric study on lateral vibration model of steel sheet pile," Journal of the Korean Industry Technology, vol. 7, no. 3, pp. 1047-1052 (Hungarian), 2010 (Korean).

[35] H. Zeilinger, "The vibro-jetting driving method," in Proceedings of the International Foundation Congress and Equipment Exposition, pp. 311-318, ASCE, Orlando, Fla, USA, 2009. 


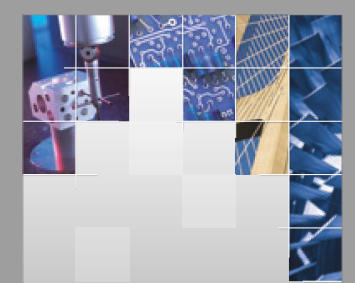

\section{Enfincering}
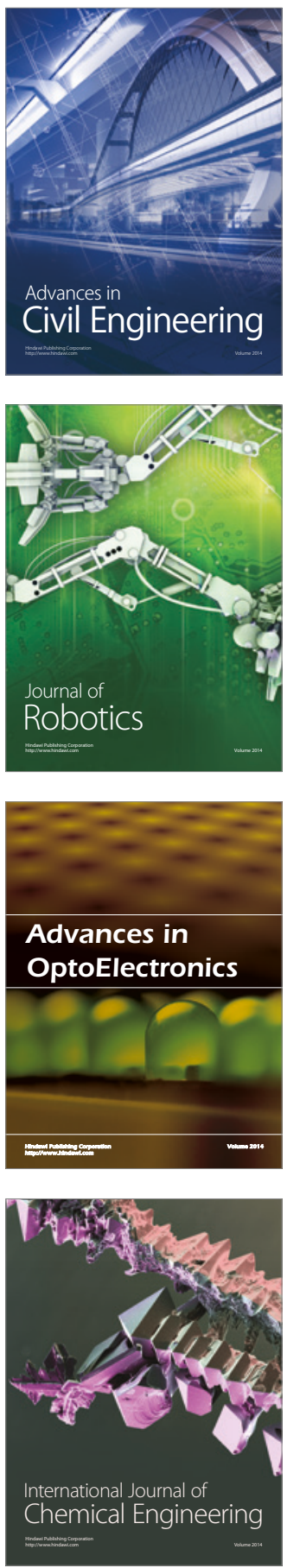

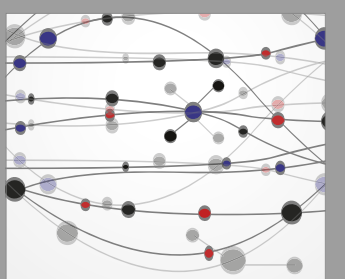

The Scientific World Journal

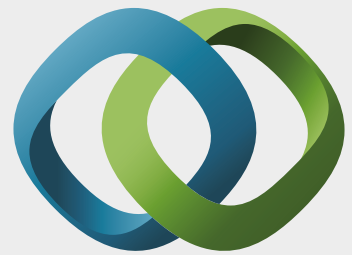

\section{Hindawi}

Submit your manuscripts at

https://www.hindawi.com
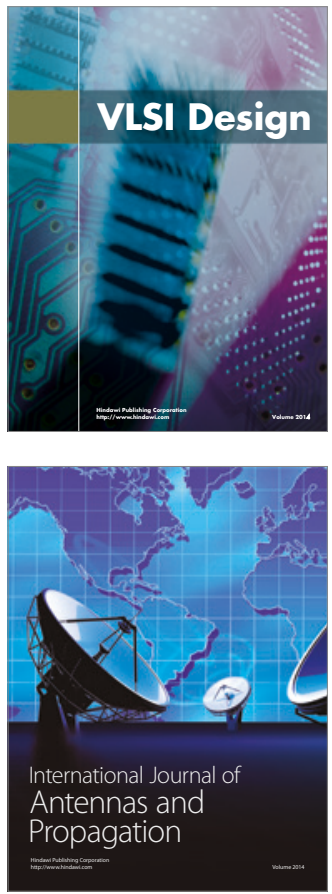

\section{Rotating}

Machinery
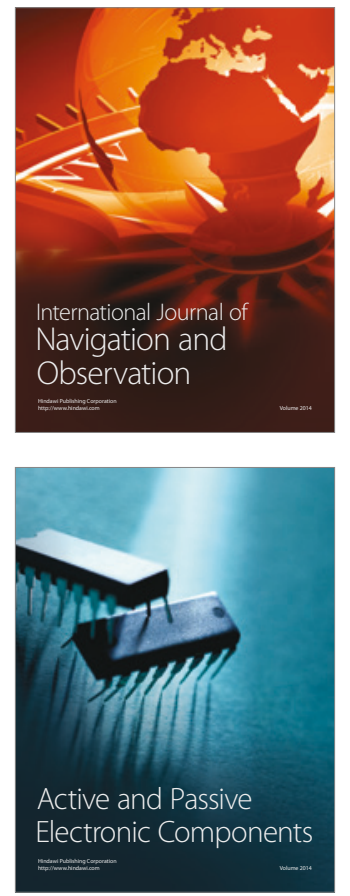
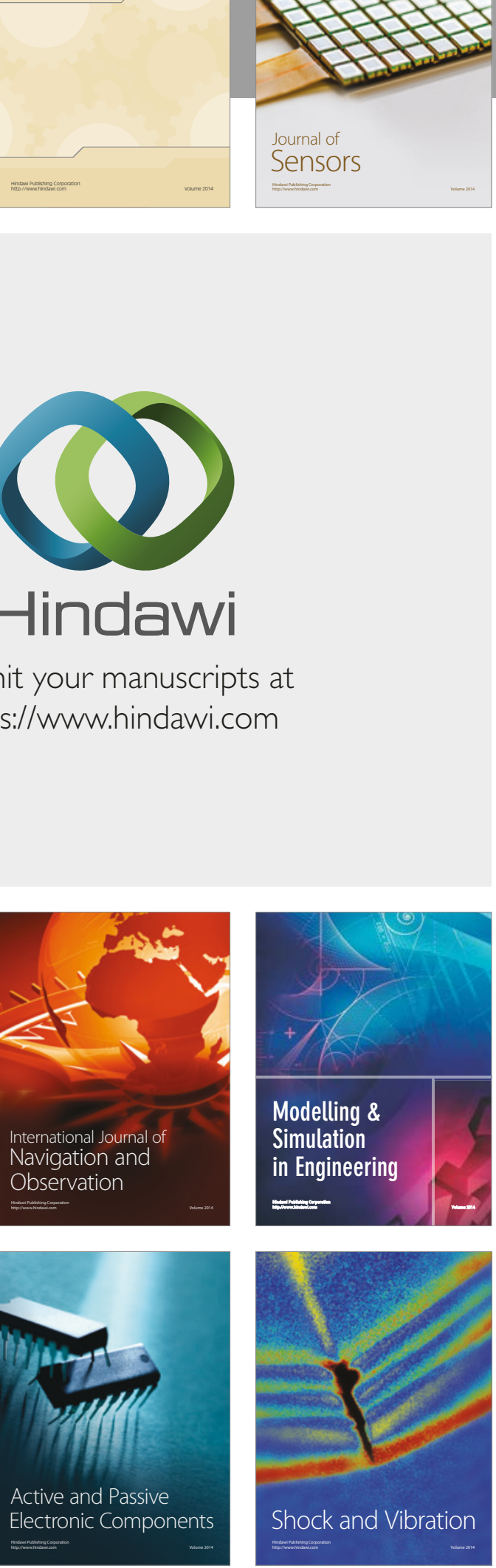
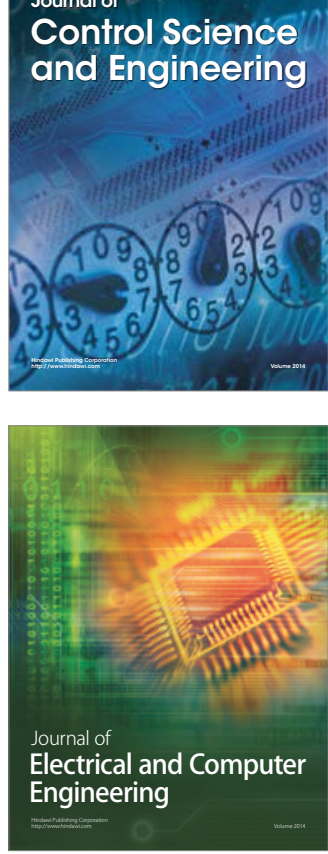

Distributed

Journal of

Control Science

and Engineering
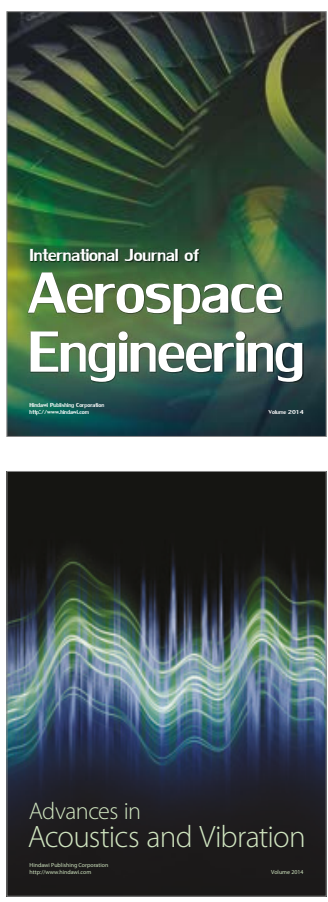

Sensor Networks 